\title{
Right ventricular function 10 years after the Mustard operation for transposition of the great arteries: analysis of size, shape, and wall motion
}

\author{
ANDREW N REDINGTON, MICHAEL L RIGBY, PAUL OLDERSHAW, \\ DEREK G GIBSON, ELLIOT A SHINEBOURNE
}

From the Brompton Hospital, London

SUMMARY Biplane right ventriculograms were obtained in 18 symptom free patients 109 (26) months (mean (SD)) after Mustard repair of transposition of the great arteries. Ventricular size, shape, and wall motion were measured from the digitised angiograms and compared with previously published data on left ventricular function after anatomical correction of transposition of the great arteries, with right ventricular function in controls, and with patients before repair of tetralogy of Fallot. Global indices of ventricular function were depressed after Mustard repair and wall motion abnormalities were common. The presence of wall motion abnormalities in this group was associated with a reduction in ejection fraction and ventricular filling rates. In four of five patients in whom an appropriate preoperative angiogram was available a similar pattern of wall motion was seen before the Mustard operation, suggesting that preoperative events may be important in determining eventual outcome.

The choice between intra-atrial repair ${ }^{1}$ or anatomical correction $^{2}$ for patients with transposition of the great arteries remains a subject of debate. Few would question the considerable impact that intra-atrial procedures have had on early and mid-term survival in these patients, ${ }^{34}$ but the ability of the right ventricle to function adequately as the systemic pumping chamber in the long term was questioned after earlier reports of right ventricular dysfunction after these operations. ${ }^{56}$ Anatomical correction has the theoretical advantage of restoring the left ventricle as the systemic ventricle. Indeed several postoperative studies showed global left ventricular function that almost equalled that of the normal left ventricle. ${ }^{7-10}$ The higher early mortality of the operation was perhaps its biggest drawback, but with improved surgical techniques the operation is being performed earlier in life, and surgical mortality has improved. Comparisons of functional results after these operations are therefore of increasing importance.

In this study, data on right ventricular function were obtained from a large group of patients studied

\footnotetext{
Requests for reprints to Dr Andrew N Redington, Department of Paediatric Cardiology, Brompton Hospital, Fulham Road, London SW3 6HP.

Accepted for publication 16 June 1989
}

7-10 years after a Mustard operation for simple transposition of the great arteries. We compared these data with our earlier data on right ventricular function in controls, ${ }^{11}$ in patients with right ventricular pressure load, ${ }^{12}$ and with left ventricular function studied early after anatomical correction. ${ }^{10}$

\section{Patients and methods}

PATIENTS AFTER THE MUSTARD PROCEDURE

This group consisted of 18 patients (mean (SD) age 118 (24) months) studied 109 (26) months after a Mustard operation for repair of transposition of the great arteries. They were the group with the longest follow up at the Brompton Hospital. All patients had either an intact ventricular septum or a small ventricular septal defect that was haemodynamically unimportant and did not require surgical closure. Seventeen of the patients had required balloon atrial septostomy during the neonatal period. The mean (SD) age at Mustard operation was nine (6) months.

All were symptom free at the time of routine review in the outpatient department. Informed consent was obtained from the parents of each patient. Some of the patients in this group underwent, in addition, detailed haemodynamic studies, and this data is presented elsewhere. ${ }^{13}$ 
456

PATIENTS AFTER ANATOMICAL CORRECTION

This group consisted of 15 patients, nine with simple transposition of the great arteries and six with transposition and a large ventricular septal defect. ${ }^{10}$ They were studied 20 (15) months after anatomical correction. Their age at operation ranged from one day to 73 months. Those with simple transposition were operated on significantly earlier $(p<0.02$, Mann-Whitney $U$ test). Six patients had a significant obstruction of the right ventricular outflow tract (mean gradient $54 \mathrm{~mm} \mathrm{Hg}$ ), but no patient had obstruction of the left ventricular outflow tract or aortic regurgitation. Data from some of the patients in this group were included in an earlier report. ${ }^{13}$

\section{OTHER GROUPS}

We have earlier reported data on right ventricular function in 10 normal adults, ${ }^{11}$ and in 12 patients studied before repair of tetralogy of Fallot. ${ }^{12}$ These data gave us the opportunity to compare right ventricular function after the Mustard operation with right ventricular function under normal loading conditions and when the right ventricular pressure is at a systemic level. These groups are historical controls and conclusions drawn from such a comparison must be interpreted with caution.

\section{ANALYSIS OF ANGIOGRAMS}

Biplane right ventriculograms were obtained in $30^{\circ}$ right oblique and $60^{\circ}$ left oblique projections, and single plane left ventriculograms were obtained in $30^{\circ}$ right oblique projections. Our method of analysis has been reported in detail elsewhere. ${ }^{11}$ Each ventriculogram was digitised frame by frame and the following indices of function were derived from the stored data.

\section{(a) Ventricular volumes}

End diastolic, end systolic, and stroke volumes were measured from the volume-time curves and were normalised for body surface area $\left(\mathrm{ml} / \mathrm{m}^{2}\right)$. The ejection fraction was calculated in the usual way. Ventricular filling and emptying rates were normalised by dividing by end diastolic volume.

\section{(b) Volume independent indices}

Because it was difficult to compare volume dependent indices of right and left ventricular function in these patients, we analysed two further aspects of function in detail. The analysis of ventricular shape and regional wall motion has the potential advantage of being independent of absolute size and so may be of particular value in such a comparison.

Ventricular shape index.-This is a measure of the "roundness" of the cavity outline throughout the cardiac cycle. Derived as $4 \pi$ cavity area/perimeter it
Redington, Rigby, Oldershaw, Gibson, Shinebourne

has a maximum value when the cavity outline is circular and a minimum value of 0 when there is complete obliteration of the cavity. During systole the normal left ventricle becomes less round, up to $20 \%$ of its stroke volume being ejected as a result of shape change alone. ${ }^{14}$ The index has the advantage of being independent of ventricular size and has been used to examine changes in the mechanism of left ventricular ejection in babies and children. ${ }^{710}$ The right ventricular end diastolic shape index was measured separately in the right anterior oblique and left anterior oblique views, and the change in the shape index during systole was taken as the difference between measurements at end diastole and at end ejection.

Regional wall motion.-Isometric and contour plots of regional wall motion throughout the cardiac cycle were made for each patient. This method depends on defining 40 equally spaced points around the outline of the end diastolic cavity. ${ }^{15-17}$ From each of these points the nearest point on the end systolic outline is determined and the two points are joined. The position of the endocardium throughout the cardiac cycle was measured on each of these lines and expressed in millimetres from its end diastolic position. Thus 40 plots of endocardial motion throughout the cardiac cycle were generated. A three dimensional isometric display was produced by stacking the 40 plots obliquely with each plot connected by isochrones representing successive cine frames, or alternatively a contour map was produced with each contour representing movement of the endocardium by $1 \mathrm{~mm}$ from the end diastolic position (fig 1). The times of end systole (taken as minimum cavity volume) and mital or tricuspid valve opening (corresponding to the cineframe in which unopacified blood first entered the ventricle) were marked on both displays.

Left ventricular wall motion abnormalities were assessed by comparison with previously reported normal values. ${ }^{15}$ No normal data are available for the right ventricle for this method of display. Instead wall motion was said to be abnormal if wall motion plots taken from the right oblique projection showed systolic outward motion of more than $2 \mathrm{~mm}$ in three or more adjacent segments (dyskinesia); inward motion in more than 3 adjacent segments continued beyond the time of tricuspid valve opening (isovolumic abnormalities); or if there was less than $2 \mathrm{~mm}$ of inward motion of more than 3 adjacent segments (hypokinesia).

STATISTICAL ANALYSIS

Variables were expressed as the mean (1 SD). Comparison of group data was by Student's $t$ tests when the data were normally distributed and by non- 
Table Individual data from the 18 patients after Mustard's operation

\begin{tabular}{|c|c|c|c|c|c|c|c|c|c|c|c|}
\hline $\begin{array}{l}\text { Patient } \\
\text { No. }\end{array}$ & $\begin{array}{l}E D V I \\
\left(\mathrm{ml} / \mathrm{m}^{2}\right)\end{array}$ & $\begin{array}{l}E S V I \\
\left(m l / m^{2}\right)\end{array}$ & $\begin{array}{l}S V I \\
\left(m l / m^{2}\right)\end{array}$ & $E F\left({ }^{o}{ }_{o}\right)$ & $\begin{array}{l}P F R \\
\left(s^{-1}\right)\end{array}$ & $\begin{array}{c}t P F R \\
(m s)\end{array}$ & $\begin{array}{c}P E R \\
\left(s^{-1}\right)\end{array}$ & $\begin{array}{c}t P E R \\
\text { (ms) }\end{array}$ & $R R$ (ms) & $\begin{array}{l}E D \\
\text { shape } \\
R A O\end{array}$ & $\begin{array}{l}E D C \\
\text { shapg } \\
L A \bar{Q}\end{array}$ \\
\hline 1 & 82 & 19 & 63 & 76 & $3 \cdot 7$ & 110 & $2 \cdot 16$ & 240 & 950 & 87 & $81 \cong$ \\
\hline 2 & 107 & 43 & 64 & 59 & $2 \cdot 7$ & 30 & $3 \cdot 8$ & 100 & 540 & 82 & 74 음. \\
\hline 3 & 77 & 31 & 46 & 59 & $4 \cdot 3$ & 40 & $5 \cdot 3$ & 100 & 460 & 82 & $84 \stackrel{\omega}{\supset}$ \\
\hline 4 & 89 & 34 & 54 & 61 & $3 \cdot 5$ & 120 & 3.9 & 70 & 480 & 80 & $91 \overline{\mathrm{D}}$ \\
\hline 5 & 78 & 49 & 29 & 37 & $1 \cdot 38$ & 90 & $1 \cdot 2$ & 100 & 820 & 91 & 82 으 \\
\hline 6 & 64 & 28 & 36 & 56 & $2 \cdot 9$ & 110 & $2 \cdot 8$ & 80 & 620 & 89 & 80 心 \\
\hline 7 & 104 & 77 & 27 & 26 & $2 \cdot 38$ & 40 & $1 \cdot 1$ & 90 & 300 & 90 & $75 \vec{\sim}$ \\
\hline 8 & 53 & 27 & 26 & 49 & 3.9 & 80 & $3 \cdot 3$ & 110 & 450 & 92 & $70 \div$ \\
\hline 9 & 76 & 37 & 39 & 51 & 2.9 & 50 & $3 \cdot 7$ & 150 & 500 & 90 & $78=$ \\
\hline 10 & 60 & 16 & 44 & 73 & $5 \cdot 5$ & 80 & $7 \cdot 5$ & 110 & 440 & 75 & $74 \omega$ \\
\hline 11 & 66 & 33 & 33 & 50 & $4 \cdot 1$ & 60 & 3.9 & 90 & 400 & 85 & 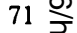 \\
\hline 12 & 70 & 51 & 19 & 27 & $1 \cdot 1$ & 60 & $2 \cdot 0$ & 110 & 540 & 89 & 75 引 \\
\hline 13 & 107 & 64 & 43 & 40 & $1 \cdot 1$ & 100 & $2 \cdot 3$ & 120 & 800 & 78 & 95 ') \\
\hline 14 & 107 & 48 & 59 & 55 & $4 \cdot 2$ & 110 & 4.9 & 190 & 1100 & 94 & $89 N$ \\
\hline 15 & 126 & 85 & 41 & 32 & $1 \cdot 79$ & 100 & $1 \cdot 8$ & 150 & 800 & 80 & 81 " \\
\hline 16 & 120 & 63 & 57 & 47 & $3 \cdot 3$ & 100 & $2 \cdot 6$ & 200 & 980 & 92 & $-\vec{c}$ \\
\hline 17 & 72 & 44 & 28 & 38 & $2 \cdot 7$ & 160 & $2 \cdot 2$ & 110 & 760 & 78 & 76 ज \\
\hline 18 & 63 & 27 & 36 & 57 & $4 \cdot 5$ & 110 & 3.4 & 110 & 500 & 94 & 82 윽 \\
\hline
\end{tabular}

EDVI, end diastolic volume index; ESVI, end systolic volume index; SVI, stroke volume index; EF, ejection fraction; PFR, peak filling rate; PER, peet ejection rate; t, time; RAO, right anterior oblique; $\mathrm{LAO}$, left anterior oblique.

parametric tests (Mann-Whitney $U$ test) when they were not. Correlation of variables was examined by linear regression by the method of least squares.

\section{Results}

The table shows data from individual patients after operation. The results below are given as means (1 SD).

\section{GLOBAL RIGHT VENTRICULAR FUNCTION}

No patient had significant tricuspid regurgitation. The end diastolic volume index was $84.4(22) \mathrm{ml} / \mathrm{m}^{2}$. The end systolic volume index was 43 (19) and the stroke volume index was $41(13.5) \mathrm{ml} / \mathrm{m}^{2}$. The ejection fraction ranged from 26 to $76 \%$ (mean 50 $(14)^{\circ}{ }_{0}$; seven patients had an ejection fraction of $<50 \%$. The peak filling rate, corrected for end diastolic volume, was $3 \cdot 1(1 \cdot 2) \mathrm{s}^{-1}$ and correlated $(\mathrm{r}=$ $0 \cdot 76, p<0.001)$ with the ejection fraction. A similar relation between peak ejection rate and ejection fraction was also found $(r=0.68, p<0.001)$.

The end diastolic shape index was $86(6)$ in the right anterior oblique projection and $79(7)$ in the left anterior oblique projection. The systolic shape change was $7 \cdot 6(5) \%$ and $3 \cdot 6(4 \cdot 3) \%$ for right and left oblique projections respectively.

\section{REGIONAL RIGHT VENTRICULAR FUNCTION}

Examination of regional wall motion plots showed a "normal" pattern in nine patients (fig 1). The remainder showed one or more of the abnormalities described in the methods section. Of these nine patients, four had areas of hypokinesis, five showed areas of systolic dyskinesis (affecting the inflow portion of the right ventricle in four (fig 2), and there were isovolumic abnormalities in three, all of whom showed areas of inward wall motion after the time of tricuspid valve opening (fig 3 ).

Comparison of the subgroup of nine patients with wall motion abnormalities with nine with a "normal" pattern showed differences in global function. The right ventricular ejection fraction was lower in those with abnormalities (40 (11.5) v $59(9.5) \%, \mathrm{p}=$ $0.0015)$ as was the peak filling rate $(3.8(0.9) v 2.4$ $\left.(1.2) \mathrm{s}^{-1}, \mathrm{p}=0.018\right)$. There was a tendency for the end systolic volume index to be higher in those with abnormal wall motion (35 (15) $v 52(20) \mathrm{ml} / \mathrm{m}^{2}, \mathrm{p}=$ $0 \cdot 06)$.

In view of these findings we studied the preoperative angiograms; 16 angiograms were available for review, but unfortunately only five of these were of adequate quality and in an appropriate angiographic projection for subsequent analysis. One was from a patient with "normal" postoperative wall motion. The preoperative wall motion plots were also normal in this patient. The remaining four angiograms came from patients shown to have postoperative wall motion abnormalities. Of these, one patient had "normal" preoperative right ventricular wall motion; the rest were abnormal. The similarity between preoperative and postoperative wall motion plots was striking, despite the long interval between studies. Figure 3 shows the isometric plots taken from preoperative and postoperative angiograms. Despite an interval of nine years, the two plots are similar. Both show areas of outflow tract hypokinesia, with peak inward movement of the inflow tract occurring after tricuspid valve opening. There was no relation between any of the indices and either age at operation or time from operation. 
COMPARISON WITH OTHER GROUPS

Left ventricle after anatomical correction ${ }^{10}$

The right ventricle was larger after a Mustard operation than the left ventricle was after anatomical correction at end diastole (anatomical correction 64 (21) $\mathrm{ml} / \mathrm{m}^{2}$ ), and end systole (anatomical correction
Redington, Rigby, Oldershaw, Gibson, Shinebourn Minimum cavity Tricuspid valve volume $\downarrow$ opening

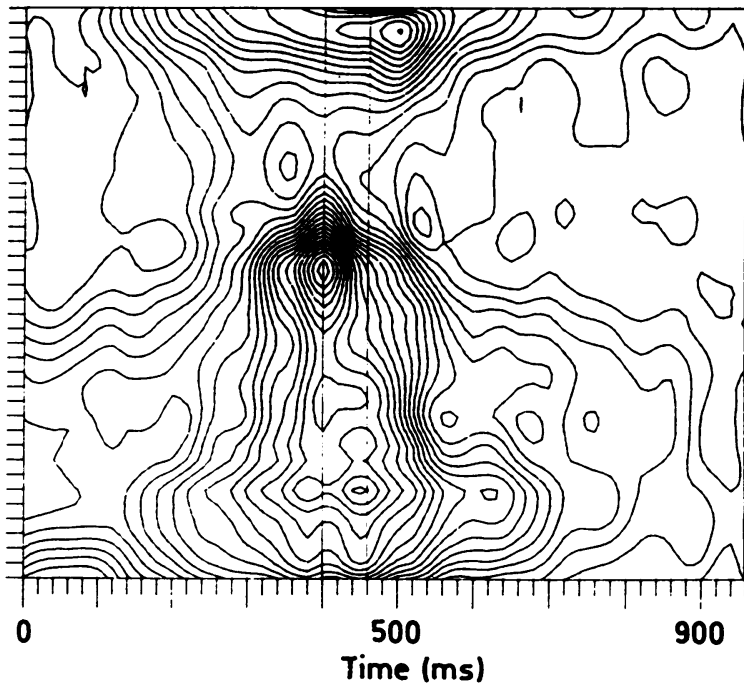

Time (ms)

Fig 1 Right ventricular wall motion plot from a patient after Mustard's operation. Wall motion is normal.

$18(9) \mathrm{ml} / \mathrm{m}^{2}$ ). The ejection fraction was lower in the subgroup of patients with transposition and ventricular septal defect than in those with simples transposition $(62(9) \% v 76(10) \%)$ but the righto ventricular ejection fraction after a Mustard operation was lower than in the anatomical correction

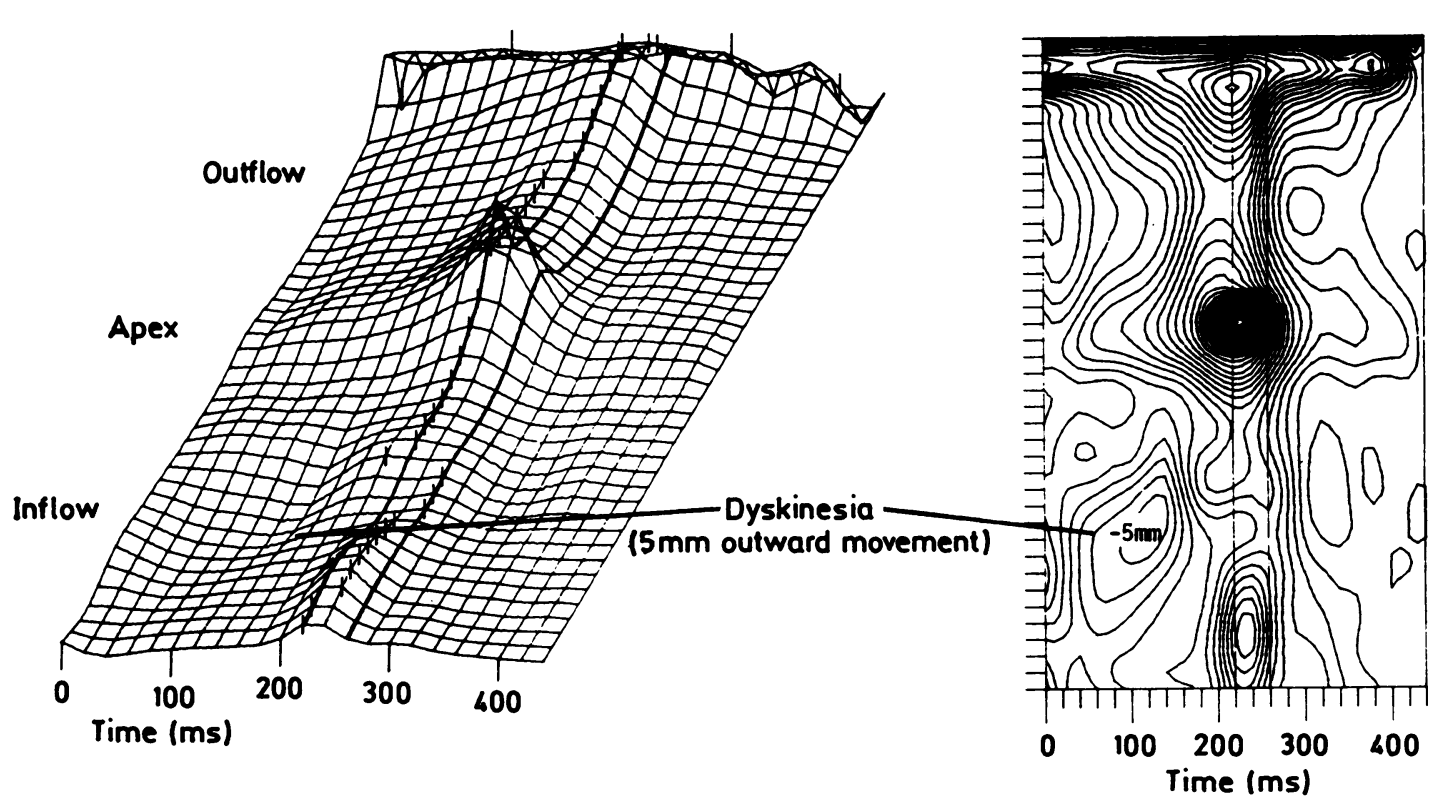

Fig 2 Right ventricular wall motion plot from a postoperative patient. There is an area of systolic dyskinesis ( $5 \mathrm{~mm}$ outward movement) of the inflow portion of the ventricle. 

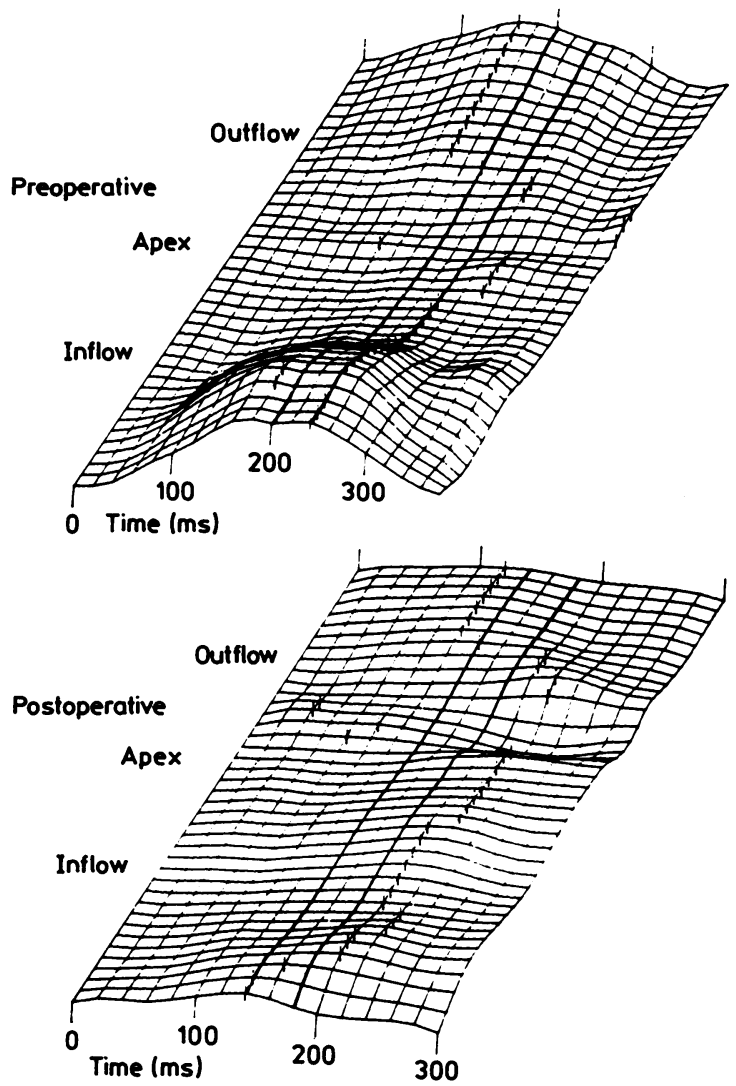

Fig 3 Right ventricular wall motion plots from a patient before and eight years after a Mustard operation. The overall pattern of motion is similar with outflow tract hypokinesia and an area of apical dyskinesia.

group as a whole $(69(10) \%)$ and in the two subgroups. The peak ventricular filling rate was much lower in the right ventricle after a Mustard operation (anatomical correction $7.6(2.0) \mathrm{s}$ ), but the $R R$ interval was longer in these patients. When corrected for heart rate the significant difference between the two groups persisted.

The end diastolic shape index measured from the right anterior oblique view was similar in the two groups (anatomical correction $83(6) \%$ ), but the change in shape during systole was less after the Mustard operation (anatomical correction 12.9 $(5 \cdot 1) \%)$, indicating possible differences in the mechanism of ejection in the two groups.

Regional wall motion abnormalities were common after anatomical correction. These were discussed fully in an earlier report. ${ }^{10}$ The most common abnormality was anterior hypokinesia, with delay of onset of inward wall motion of the affected segments. This pattern was seen in six of the patients in this study. In two other patients there was inferior hypokinesia and segmental early relaxation during the isovolumic relaxation period, respectively. There was no difference in the frequency of wall motion abnormalities between the two groups.

\section{COMPARISON WITH THE NORMAL AND}

PRESSURE-LOADED RIGHT VENTRICLE

After the Mustard operation, patients had a higher end diastolic volume, end systolic volume $(p<$ 0.001 ), and a lower ejection fraction than controls. The comparison with the unoperated patients with tetralogy of Fallot ${ }^{12}$ (when right ventricular pressure is at systemic levels) is perhaps more useful. Again end diastolic and end systolic volumes were higher after a Mustard operation and the ejection fraction was lower. There was no difference in the $R R$ irterval between the groups, but the peak filling rate was considerably lower after the Mustard operation.

\section{Discussion}

The major concern after intra-atrial repair of transposition of the great arteries is whether the right ventricle can perform adequately as the systemic ventricle throughout life. Anatomical correction restores the left ventricle as the systemic pumping chamber, and now that the high early mortality ${ }^{18}$ has improved the central question, in terms of the long term outlook for these patients, is whether left ventricular function after anatomical correction is better than right ventricular function after the Mustard operation?

The most logical approach to answering this question seems to be to compare right ventricular function after the Mustard operation with left ventricular function after anatomical correction. But is this a valid comparison? In the normal heart the right ventricular end diastolic volume is higher, the ejection fraction is lower, and the pressure-volume characteristics are substantially different than those of the left ventricle. ${ }^{11}$ Indeed these differences have been highlighted as reasons why it may be invalid to use indices of ventricular function, validated in the left ventricle, to assess right ventricular function. ${ }^{12}$ The situation in patients after repair of transposition is somewhat different, however. Under these circumstances, the systemic ventricle (be it a left or right ventricle) is expected to perform the same function. Indeed, results in this study and in others ${ }^{19} 20$ show that right ventricular function in some patients after intra-atrial repair may be comparable to that of the normal left ventricle. There must therefore be one basic assumption when the two postoperative groups are compared-that is that under ideal circumstances the right ventricle can perform in the same way as the normal left ventricle. 
How does right ventricular function after the Mustard procedure compare with left ventricular function after anatomical correction? The volume of the right ventricle seems to increase after the Mustard procedure to a value that is higher than normal and higher than the pressure-loaded right ventricle. The biggest difference between these groups was in the end systolic volume index, however. This difference was the major determinant of the lower ejection fraction seen after the Mustard operation. Indeed, when compared with the left ventricle after anatomical correction, the ejection fraction was considerably reduced in the Mustard group as a whole, although in eight of the 18 patients the ejection fraction was $>55 \%$. Similar results have been reported in previous studies of smaller numbers of patients with simple transposition after intra-atrial repair. ${ }^{1920}$

Right ventricular shape has not been examined in detail previously. The normal left ventricle becomes progressively less round during systole, and up to $20 \%$ of the stroke volume is ejected as a direct consequence of this shape change. ${ }^{14}$ This is an efficient mechanism because ejection can occur with less global myocardial fibre shortening, which is an energy consuming process. Our data ${ }^{10}$ and that of others ${ }^{7}$ showed that this mechanism is preserved in the left ventricle after anatomical correction. After the Mustard operation the end diastolic shape index of the right ventricle was similar to that of the left ventricle after anatomical correction. But the reduction in shape index during systole after the Mustard operation was much less, suggesting that a shape change makes little contribution to right ventricular ejection after the Mustard operation; so this must be almost entirely dependent upon myocardial fibre shortening.

In addition to these differences in systolic function, there was evidence of impairment of diastolic function. The peak rate of right ventricular early diastolic filling after the Mustard operation was less than that of the left ventricle after anatomical correction and that of the right ventricle in tetralogy of Fallot before radical repair. It is possible that this was because the size of the atrial reservoir was reduced by a restrictive intra-atrial baffle. None the less, the filling rates after a Mustard operation were similar to those seen in the right ventricle after repair of tetralogy of Fallot; and a similar mechanism of reduced diastolic compliance, perhaps secondary to diffuse or focal fibrosis, may be invoked. ${ }^{12}$ This is important because diastolic abnormalities may relate to abnormalities of the subsequent systole. The strong correlation between peak filling rate and ejection fraction in this study supports this concept and accords with the work of Sideris et al who showed a similar relation between right ventricular diastolic and systolic function in these patients. ${ }^{21}$

There was no relation between any of these indices and age at operation or time from operation in either of the two groups. Others reported this lack of correlation between length of time from operation and impairment of ventricular function ${ }^{22}$ and in a recently published longitudinal study there was no deterioration in ejection fraction measured over a five year period..$^{23}$ If the impairment of right ventricular function after the Mustard operation is caused by the long term effects of increased afterload, ${ }^{24}$ this is somewhat surprising. It is possible that preoperative and operative factors are more important in determining postoperative function. Boucek et al reported that concentrations of creatine kinase $\mathrm{MB}$ isoenzyme were high before operation. ${ }^{25}$ In another study the preoperative right ventricular ejection fraction was low. ${ }^{24}$

Half of our patients had abnormal wall motion plots. Furthermore, when the group of patients with abnormal plots was compared with a group with no gross abnormalities, those with abnormal plots had a lower right ventricular ejection fraction and peak ventricular filling rate. These observations are supported by data from a cross sectional echocardiographic study showing dyskinetic right ventricular wall movement in three patients with congestive heart failure but not in others who were clinically well after the Mustard operation. ${ }^{26}$

Even more important, perhaps, was the finding that four of the five patients in whom an appropriate preoperative right ventriculogram was available showed an abnormal dyskinetic pattern of right ventricular wall motion before operation and in three of these four patients the preoperative wall motion plots were similar. Further longitudinal studies are required but it seems that preoperative and operative factors may be important in determining postoperative function, there being little evidence of deterioration with time in these patients.

The clinical importance of these data is less clear. While the finding of ejection fractions of $<40 \%$ in six of our 18 patients is worrying, all of the patients were symptom free and leading normal lives. It is possible that deterioration in function will become manifest as follow up in these patients lengthens, and it must be recognised that these patients represent a highly selected group. Global left ventricular function is well preserved early after anatomical correction, as shown by our own and other data, but wall motion abnormalities are common. However, follow up in this group of patients is even shorter than that for those who had a Mustard operation and the significance of these abnormalities and the possible long term effects of right ventricular outflow tract 
obstruction $^{13}$ and aortic regurgitation, ${ }^{27}$ which are becoming increasingly recognised, are unknown. The selection of the appropriate operation in the individual patient remains difficult. It may be that formal assessment of right and left ventricular function before operation will enable more appropriate selection.

We thank Dr David Hughes and Mrs Susan Jones for their help in undertaking this study.

\section{References}

1 Trusler GA, Mustard WT. Palliative and reparative procedures for transposition of the great arteries. Ann Thorac Surg 1974;17:410-21.

2 Jatene AD, Foutes VF, Paulista PP, et al. Anatomic correction of transposition of the great vessels. $J$ Thorac Cardiovasc Surg 1976;72:364-70.

3 Mahony L, Turley K, Ebert P, Heyman MA. Longterm results after atrial repair of transposition of the great arteries in early infancy. Circulation 1982;66: 253-7.

4 Arciniegas E, Farooki ZQ, Hakimi M, Perry BL, Gree EW. Results of the Mustard operation for dextrotransposition of the great arteries. $J$ Thorac Cardiovasc Surg 1981;81:580-5.

5 Graham TP, Atwood GF, Boucek RJ, Boerth RC, Bender HW. Abnormalities of right ventricular function following Mustard's operation for transposition of the great arteries. Circulation 1975;52:678-84.

6 Mee RBB. Severe right ventricular failure after Mustard or Senning operation. J Thorac Cardiovasc Surg 1986;92:385-90.

7 Arensman FW, Radley-Smith R, Yacoub $\mathrm{MH}$, et al. Catheter evaluation of left ventricular shape and function one or more years after anatomic correction of transposition of the great arteries. Am J Cardiol 1983;52:1079-83.

8 Sievers HH, Lange PE, Onnasch DGW, et al. Influence of the two-stage anatomic correction of simple transposition of the great arteries on left ventricular function. Am J Cardiol 1985;56:514-9.

9 Borow KM, Arensman FW, Webb C, Radley-Smith R, Yacoub MH. Assessment of left ventricular contractile state after anatomic correction of transposition of the great arteries. Circulation 1984;69:106-12.

10 Lincoln C, Redington AN, $\mathrm{Li} \mathrm{K}$, Mattos $\mathrm{S}$, Shinebourne EA, Rigby ML. Anatomical correction for complete transposition and double outlet right ventricle: intermediate assessment of functional results. Br Heart J 1986;56:259-66.

11 Redington AN, Gray HH, Hodson ME, Rigby ML, Oldershaw RJ. Characterisation of the normal right ventricular pressure-volume relation by biplane angiography and simultaneous micromanometer pressure measurements. Br Heart $J$ 1988;59:23-30.

12 Redington AN, Oldershaw RJ, Shinebourne EA, Rigby ML. A new technique for the assessment of pulmonary regurgitation and its application to the assessment of right ventricular function before and after repair of tetralogy of Fallot. $B r$ Heart $J$ 1988;60: 57-65.

13 Carvalho JS, Shinebourne EA, Busst CM, et al. Haemodynamic findings in asymptomatic children 10 years after Mustard's operation for transposition of the great arteries. Int $J$ Cardiol (in press).

14 Gibson DG, Brown DJ. Continuous assessment of left ventricular shape in man. Br Heart J 1975;37:904-10.

15 Gibson DG, Fleck E, Rudolph W. Effect of postextrasystolic potentiation on amplitude and timing of regional left ventricular wall motion in ischaemic heart disease. Br Heart $J$ 1983;49:466-76.

16 Hui WKK, Gibson DG. Mechanisms of reduced ventricular filling rate in coronary artery disease. $\mathrm{Br}$ Heart $J$ 1983;50:362-71.

17 Gibson DG, Mehmel H, Schwarz F, Li K, Kübler W. Asynchronous left ventricular wall motion early after coronary thrombosis. Br Heart J 1986;55:4-13.

18 Bical O, Hazan E, LeCompte $\mathrm{Y}$, et al. Anatomic correction of transposition of the great arteries associated with ventricular septal defect: midterm results in 50 patients. Circulation 1984;70:891-7.

19 Okuda H, Nakazawa M, Imai Y, et al. Comparison of ventricular function after Senning and Jatene procedures for complete tansposition of the great arteries. Am J Cardiol 1985;55:530-4.

20 Graham TP, Burger J, Bender HW, Hammon JW, Boucek RJ, Appleton S. Improved right ventricular function after intra-atrial repair of transposition of the great arteries. Circulation 1985;72(suppl II): 45-51.

21 Sideris EB, Olley PM, Spooner E, Farina M, Shaher R. Ventricular pressure-volume relations after the intraatrial baffle operation for transposition of the great arteries. Am Heart J 1982;104:1045-53.

22 Hagler DJ, Ritter DG, Mair DD, et al. Right and left ventricular function after the Mustard procedure for transposition of the great arteries. Am J Cardiol 1979; 44:276-83.

23 Wong KY, Venables AW, Kelly MJ, Kalff V. Longitudinal study of ventricular function after the Mustard operation for transposition of the great arteries: a long term follow-up. $B r$ Heart $J$ 1988; 60:316-23.

24 Jaymakani JMM, Canent RV. Preoperative and postoperative right ventricular function in children with transposition of the great arteries. Circulation 1974; 50(suppl II):39-45.

25 Boucek RJ, Kasselberg AG, Boerth RC, Parrish MD, Graham TP. Myocardial injury in infants with congenital heart disease: evaluation by creatine kinase $\mathrm{MB}$ isoenzyme analysis. $A m J$ Cardiol 1982;50: 129-34.

26 Trowitczsch E, Colan SD, Sanders SP. Global and regional right ventricular function in normal infants and infants with transposition of the great arteries after Senning operation. Circulation 1985;72: 1008-14.

27 Helgason $\mathrm{H}$, Hougen TJ, Jacobs $\mathrm{M}$, et al. Hemodynamic results of primary anatomic repair of transposition of the great arteries. Transactions of the 22nd World Congress of Paediatric Cardiology 1985. 